\title{
$\widehat{A}$ Madridge \\ madridge Journal of Dentistry and Oral Surgery \\ Interconnecting Scientific World
}

Open Access

\section{Prosthetic Rehabilitation for the Missing Bulbus Oculi Due to Eye Enucleation (Fabricated and Non- Fabricated)}

\author{
Haryo M. Dipoyono ${ }^{1 \star}$, Gunawan S Sarjono ${ }^{2}$, Iwa A Sakti ${ }^{2}$ Lina $^{2}$, and Srada Putra ${ }^{2}$ \\ ${ }^{\prime}$ Department of Prosthodontics, Faculty of Dentistry, Gadjah Mada University, Yogyakarta, Indonesia \\ ${ }^{2}$ Student of Prosthodontic Specialist Program, Faculty of Dentistry, Gadjah Mada University, Yogyakarta, Indonesia
}

\section{Article Info

\author{
*Corresponding author: \\ Haryo M. Dipoyono \\ Department of Prosthodontics \\ Faculty of Dentistry \\ Gadjah Mada University \\ Yogyakarta, Indonesia \\ E-mail: dipoyono@yahoo.com
}

Received: September 29, 2016

Accepted: October 14, 2016

Published: March 3, 2017

Citation: Dipoyono HM, Sarjono GS, Sakti IA, Lina, Putra S. Prosthetic Rehabilitation for the Missing Bulbus Oculi Due to Eye Enucleation (Fabricated and Non-Fabricated). Madridge J Dent Oral Surg. 2017; 2(1): 38-40.

doi: $10.18689 / \mathrm{mjdl}-1000109$

Copyright: @ 2017 The Author(s). This work is licensed under a Creative Commons Attribution 4.0 International License, which permits unrestricted use, distribution, and reproduction in any medium, provided the original work is properly cited.

Published by Madridge Publishers

\begin{abstract}
Background: Losing eyeball is a process that caused both medically and psychologically traumatic. One of many drawback of losing eyeballs is vision loss. The impact of psychological aspect is the feeling of inferiority as well as social acceptance from society.

Objective: This case report aims to provide information on the making of non-fabricated individual prosthetic eyeball using acrylic resin material.

Case Report: 52 years old gentleman came to the Prosthodontic Clinic Dental Hospital, Faculty of Dentistry, Gadjah Mada University to make prosthetic eyeball after surgery to remove the eyeball two months ago due to granuloma. The patient had been using previously fabricated ocular prostheses. Patient management are anamnesis, clinical examination, individual custom trays making, wax modeling and sclera try in, acrylic processing, and determining the location and diameter of the iris, and then the insertion of the prosthetic eyeball.
\end{abstract}

Conclusion: Non-fabricated ocular prostheses can improve the patient's appearance, and by restoring the appearance would increase the confidence of patient and be accepted in his society.

Keywords: Prosthetic rehabilitation; Fabricated and Non Fabricated.

\section{Introduction}

Eye is a sensory organ that is vital for human life. It plays a role not only as one of the sensoric organs but also an essential component of facial expressions and so it is an important part in a man's facial appearance. Losing an eye would not only cause a person to experience disability function, but also affects the aesthetical appearance [1]. Anopthalmos is a situation where there is no eyeball in the eye socket. Accident on the eye is the most common cause and the main reason for removal of the eyeball. The other cause that made eyeball have to be lifted is the presence of malignancy, growth abnormalities, infections and cosmetic problems. Abnormalities caused by loss of the eyeball that made physical and psychological problems is a serious condition to handle so that eye prosthetic making is essential to improve the patient physical and psychological healing.

Eyeball removal surgical procedure often done by ophtalmologist including [2]: Eviceration: partial removal of the contents of the eyeball, leaving only the sclera and sometimes cornea. The most suitable prostheses for this patient were non-fabricated prosthetic or shell-shaped scleral shell prostheses; Enucleation: enucleation of whole 
eyeball after the outer eye muscles and nerves were cut. The suitable type of prostheses for patients with this defect was conventional ocular prostheses or implant supported prostheses. The surgeon will place the implant in the capsule of the eye muscles to fill the defect and support the muscles and eyelids. The use of the implant allows muscle binding of the eye to move a prostheses; Exstenteration: whole eyes tissue lifted (including the eye and surrounding tissue). This procedure is generally done in the case of cancer.

Art to create an ocular prothesis has been known since the time of ancient Egypt. Simple prostheses that made from white shells at 3000 years BC were discovered. Further development for prosthesis were stone, pottery, bronze gold, to silver. Ambrose Pare (1510-1590) was the first French person who uses a mixture of glass and porcelain. In 1835 ocular prostheses had been mass-produced in Germany. The most versatile material used for making prosthesis was plastic type that evolved into an acrylic ocular prostheses. In today's developed orbital implant use, consisted of material alloplastik planted at tissue under the conjunctiva to fill the space of the eyeball. The use of implants have the advantage of having better retention and acceptable to patients [3].

There is a variety of techniques that have been documented in literature for the patient management of ocular prothesis. That were custom eye and stock eye. The advantage of using stock eye was less time needed, less disadvantage of aesthetic weakness bad and sometimes not very precise in size. Non-fabricated ocular prostheses was more time consuming and more complex but it provide better aesthetic [4].

\section{Case Report}

A 52 years old gentleman admitted to Prosthodontics Departement Dental Hospital, Faculty of Dentistry, Gadjah Mada University had the complained of uncomfortable with ocular prostheses placed by an ophthalmologist. This patient had undergone enucleation of the left eye procedure two months ago due to glaucoma. On clinical examination, the patient's left eye had been removed but there is still a muscle at the base of the socket and wound healing has been running perfectly. Patients expressed willingness to publish the treatment to be performed.

\section{Procedure}

Informed consent were signed by the patient after all informations regarding the treatment have been explained.

Initial impression of defect area were made using irreversible hydrocolloid (Aroma Fine DF III, GC) using $5 \mathrm{~mm}$ disposable syringe (Dispo van) using Miller technique. Before making impression, thin layer of petroleum jelly applied to patient's eyelashes and socket to prevent the impression material sticks to them.

Individual impression tray to adapt the defect area made by using clear auto polymerization resin. Final impression from defect area were made using light body of polyvinyl siloxane impression material (Aquasil, Dentsply). Patient were instructed to move his eyes to right and then left, upward and downward, and finally made a circular movement so that the impression of functional defect could be taken as well as taking the palpebral movement impression.

The impression were taken out from socket and then filled until contour height using type IV dental stone (Glastone 2000, Dentsply). After the gypsum were set, keyhole were made and boxed, and then second layer filled with type III dental stone (Glastone 2000, Dentsply) to acquire 2 mold for making the ocular prosthesis). Two parts of the mold were separated and then final mold were made. Wax pattern were acquired from sprue canal and was made above the mold.

Wax pattern were made using modelling wax (Modelling wax, Dentsply). The precision of wax pattern evaluated by observing the extension to fornix. Curvature height must be in the center of the pupil and palpebral opening must be the same with patient eye.

Distance were measured from face midline to the center of pupil and same distance of the left side were marked and carved on wax pattern. Wax pattern were invested and processed using heat cured acrylic resin (TruTone heat cured acrylic resin, Dentsply). Try in using plain sclera were done, pasien sit upright and see eye level object from 2 meter far. Supra orbital indentation, edge of inferior palpebra and iris were evaluated correspond with patient eye. Patient eye movement and its symmetrycal were checked by try in wax pattern.

Final painting were done with various color. Color choice: titanium white- ivory black-yellow ochre-burnt umbercrimson red. Patient real eye were observed under natural light and painting were done from iris edge.

Pupil were painted first imitate the real eye. Color base and dark color detail observed on natural brown, grey, or combinations of them. Apply thick layer with paintbrush, from darkest color to the brightest color using thin radial movement with striations making depth illusions. Collarette -little bit brighter from base color. Limbus - Painted from iris side and brush the color that mix iris painting and sclera then paint sclera, lining with 1,2-Dichloroethane to prevent dissolved painting.

The prosthesis were finished and polished with dental pumice (Dental Jaya, Indonesia). Prosthesis were inserted to socket after disinfected. Minor adjustment were done for comfort.

Instructions given to the patient were:

To remove the prostheses, pull the lower eyelid while see up and down so that it can fall into the hands; To insert the prostheses, pull the upper eyelid with thumb and forefinger, then push the prostheses with the other hand until the lower eyelid and until the prostheses can be tucked away in the socket; Patients were instructed to wear protheis day and night, take it off and wash with mild soap once a day; To improve the movement of the eyeball and obtain a denture surface retention, patient were suggested using ophalmic silicone liquid and must be controlled every six months. 

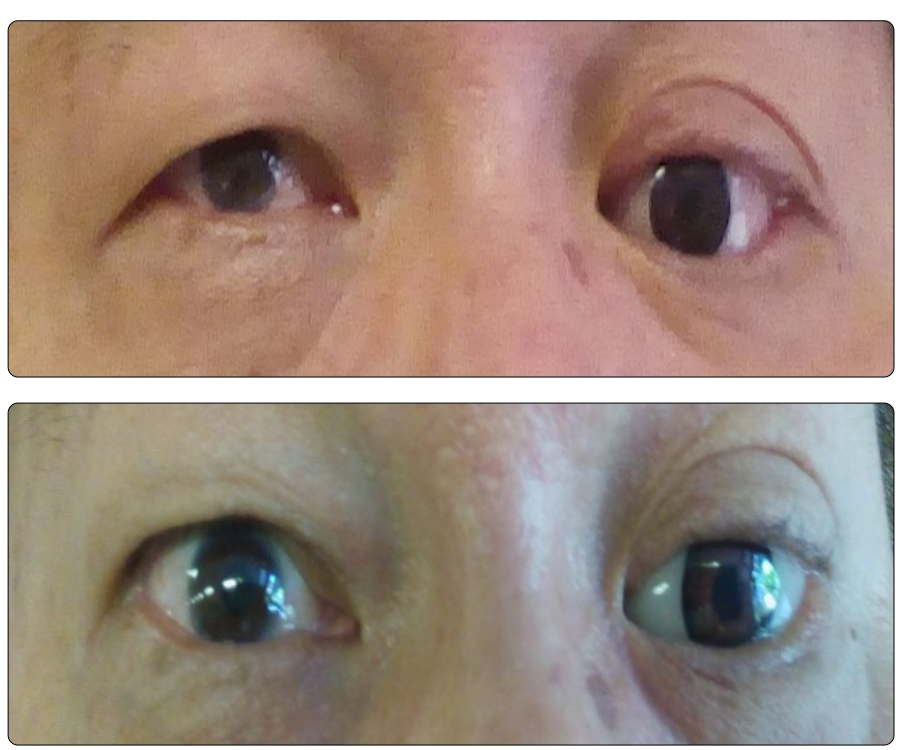

Figure 1. Comparation between fabricated ocular prosthetic (upper) and non-fabricated ocular prosthetic (lower).

\section{Discussion}

Ocular prostheses being used nowadays consists of two types, that are fabricated prostheses and custom ocular prostheses. Ideally, non-fabricated ocular prostheses is preferred because it is more stable and is able to adjust its shape to the condition of the eye socket. There are various kinds of materials used to made an ocular prostheses, such as glass material that is still used in some areas in Europe and polymethyl metacrilat that are widely used because of the durability, compatibility, easy to obtain and less expensive [5]. In these case, patients had been wearing a fabricated prosthesis before and feel discomfort compared to a custom prostheses. The size of fabricated prothesis is larger than the defect making it aesthetically unpleasing. Patients feel uncomfortable because the eye movements become limited. After wearing custom prosthesis eye, due to intimate contact of prosthesis with tissue surface of defect, movement of the custom prosthesis increase and enhanced the natural appearances of prosthesis [6,7].

\section{Conclusion}

Non-fabricated ocular prostheses has the advantage of a more comfortable and aesthetically pleasing. Although manufacturing process is more complicated and takes longer than fabricated ocular prostheses, but the advantages it has making non-fabricated ocular prostheses a better option.

Conflicts of Interest: The authors declare no conflicts of interest with this submission.

\section{References}

1. Artopolou II, Mongomery PC, Wesley PJ, Lemon JC. Digital imaging in fabrication of ocular protheses. J Prosthet Dent. 2006; 95(4): 327-30. doi: http://dx.doi.org/10.1016/j.prosdent.2006.01.018

2. Parr GR. Surgical consideration in prosthetic treatment ocular and orbital defect. J Prosthet Dent. 1983; 49(3): 379-85. doi: http://dx.doi. org/10.1016/0022-3913(83)90281-0

3. Putanikar NY, Patil AG, Shetty PK, Nagaral S, Mithaiwala HI. Prosthetic rehabilitation of a patient with ocular defect using semi-customized prothesis: a case report. J Int Oral Health. 2015; 7(4); 81-4.

4. Aidasani AN, Godbole SR, Saather S, Thombare RU. A new method to stabilize iris button during the fabrication of custom made ocular prothesis. Natl J Med Dent Res. 2013; 1: 31-3.

5. Dixit $S$, Shetty $P$, Bhat GS. Ocular prothesis in children-clinical report KUMJ. 2005; 3: 81-83.

6. Cafiero $\mathrm{CM}$, Marques $\mathrm{C}$, Danz HC. Ocular prothesis: indication to management. Can J Ophtalmol. 2015; 77(1): 24-32.

7. Shankar RY, Srinivas $K$, Singh $M$, Wangoo A. A new procedure for fabrication of custom ocular prothesis-a case report. Prav Med Rev. 2010; 4(1): 13-17. 